\title{
Directed exercises in the light of the electrical activity of muscles and kinematic characteristics of skill of the reverse body lift and its impact on the physical and skill level of the wrestlers
}

\section{${ }^{1}$ Dr. Belal Morsy Mohammed Witwit}

\section{- Introduction and research problem}

The rapid development of all sporting activities in terms of their skill components has played a role that made the sports training workers follow up everything that happens in playgrounds where competitions study showed the importance of skill components in a more detailed manner than before, in order to identify their characteristics and develop research methods to reach the ideal performance. (28)

This primarily requires the familiarity of those in charge of education and training of sports skills of the rules of motor analysis, which relies on the basic principles of kinesiology, anatomy, biomechanics and other sciences associated with the movement and technical information about any skill. This means understanding how to perform in terms of a set of information that help to determine the motor actions required to accomplish this performance at the highest possible efficiency with minimal effort. (7:197)

Layne, Epraham (1987) believes that recording the electrical activity of the muscles enables us to find out the most important muscles working during the performance and the degree of participation of each of them in the muscular activity. (21:36)

Badawi Abdel Aal (1987) refers that the use of electromyogram (EMG) has led to increased accuracy of the information about the extent of the participation of every muscle working in the movement as well as study the rhythm of muscular work, leading to the identification of mechanical muscular nervous work. (9)

Paul \& Duane (1991) stated that the use Biomechanical analysis is the scientific way for the development of training programs and performance where it works on improving performance and correcting mistakes as well as the development of technical performance and fitness programs for player and preventing injuries. (27:13)

Aweys Al-Jabali (2000) indicates that the use of analytical methods leads to knowing the details of the movement, identification the form of performance and mastering the details leading to effort save. (8: 65)

TalhaHossam El-Din (1994) believes that the identification of mechanical principles and foundations related to skill performance is the first step in detecting the causes of performance errors. Mechanical principles and foundations may differ in terms of quantity or quality depending on the patterns of skill performance and in accordance with the laws organizing the movement in the framework determinants and legal conditions for activity requirements. (31: 6)

The exercises that are similar in composition regard to the shape of motor performance performed in the game are considered direct means for major preparation for the sports level for the development of the training status of the player during the training year so that the player movement is suitable to the type of physical activity he does in terms of motor compatibility and sequence of motor performance path and direction.

Hosni Sayed Ahmed Hussein (1992) indicates that in order to achieve the technical development of performance,you should give training in which muscle work converges with the requirements of mechanical variables in terms of the direction and the motor extent.Moreover, the optimum technique in training is based on the use of contractions

\footnotetext{
${ }^{1}$ Lecturer, Of competitive and Aquatic sports Department Faculty of Physical education . Sadat city university
} 
prevailing in the exercises competition for the same muscle work type to allow the morphological adaption and the specific training is necessary during the performance of many skills. (16)

Hisham Subhi Hassan (1993) confirms the importance of the use of exercises performed in a manner consistent with the nature of the performance of the motor skill using the muscle groups working in the same skill at the same kinetic path, which has a better impact on improving the physical attributes and thus improves skill performance as training needs special physical attributes achieved through qualitative training similar to the nature of the performance. (15)

Talha Hussein Hossam El-Din (1995) believes that one of the best methods to improve skill performance during the training process is done through the training in a manner similar to a large degree with the form of the same skill and as long as the training is more specific, it would have a high return on the training process. (30:48)

Mohammed Ibrahim Shehata (2003) confirms that in order to develop the correct skill performance of the motor skills, you should use exercises that contain a similar pattern of the basic technical performance of skill and such exercises must contain the combination of the core part. (22:24)

Essam Abdul Khaliq (2003) confirms that exercises similar in performance with the basic skills are the main means for the special physical preparation and give the player the same sense required to be performed in the motor skill. (13:87)

Abdul Aziz Al-Nimr and Nariman Al-Khatib (1996) agree that performance improves better if the training is specializedforthe activity performed and contains the most important muscles involved in this activity and development of the same way to be used in competition. (2:188)

To upgrade the level of performance and increase the efficiency of achievement, it is necessary to design exercises according to the model of movement used in the competition in terms of body position, range of motion and the prevailing contractions of the groups of involved muscle.

The skill of the reverse body lift is one of the basic skills in the ground fighting in Greco-Roman Wrestling. Mohammad Reda Ruby (2005) mentions that the importance of this skill is that it is one of the important and fundamental movements to all wrestlers as its performance make the rival lose its contact with the mat and then lose control of movements and thus loses his ability to defend so it would be easy for the attacker to performthe selected movements and collect many points that make him win the game. (24:52)

Ahmed Amara and Mohammed Al Ashram (2006) mentions that skill of the reverse body lift require a great deal of muscle strength,the strength characterized with speed and flexibility, however many wrestlers do not perform. This is what referred to by Ahmed Abdel-Hamid Amara Study (2000), where he did analytical study for Republic Championship in 2005 and found that only a very small rate did not exceed $2 \%$ performed this skill during 90match in the light and medium weights andit has not been implemented in the heavy weights. (4) (5)

Nabil Hosni Al-Shourbagy (2008) indicates that skill of the reverse body lift is one of the basic skills, which greatly affects the results of games as it is one of the major technical skills that gets the highest points and it is possible from which to score touching shoulders, as well as it is difficult to defend against this skill in the case if the rival was lifted and lost contact with the mat. (25)

The research problem is that during the exercise of a researcher for wrestling,he found deficiencies in skill performance of the skill of the reverse body lift and failure to perform in 
thecorrect technique, which provides the opportunity for the player to get the full points. The reason is the lack of methods and techniques used for training, which do not take into account the musclesinvolved in skill performance as well as the correct typical technical motor path skill that addressed by scientific studies. For this reason, the researcher developed a double and overlapping program using directed exercises with weights in light of the electrolysis of muscles involved in skill and directed exercises on the mat in the light of the kinematic analysis.

\section{- Research Objectives:}

The development of a training program using directed exercises in light of (the electrolysis of muscles and the kinematic analysis) of the skill of the reverse body lift, with the aim to identify:

1- The impact of the training program on the physical variables under discussion among the individuals of the experimental group.

2- The impact of the training program on skill performance among the individuals of the experimental group.

- Research Hypotheses:

1- There are significant statistical differences between the (pre and post) measurements of the control group and the experimental group in the physical variables under discussion and the level of skill performance in favor of the post measurement.

2- There are significant statistical differences between the post measurements of the control group and the experimental group in the physical variables under discussion and the level of skill performance in favor of the experimental group.

\section{- Research Terms:}

\section{Directed Exercises:}

They are sports movements similar in composition with motor performance in the competition in terms of power, speed and motor path as well as in the direction of the muscle work. (Procedural definition)

\section{Electrical Activity of Muscles:}

It is the process of muscle response electrically by nerve signals received by the muscle from the nervous system. (20:14)

\section{Kinematic Analysis:}

It is an analytical and mathematical description of the types of movement, and not the causes of the movement. (29:129)

\section{- Research Procedures:}

\section{1- Method}

The researcher used the experimental method because of its appropriateness of the nature of the research, using theexperimental design with pre and post measurements on two groups (control and experimental).

\section{2- Research Sample}

The research sample was chosen intentionally form the players of Menoufia area team (open stage) above the 20-year season (2010/2011) and the registered players in the Egyptian Federation of Wrestling so that research community reached 23 wrestlers and (7) wrestlers were chosen to conduct the surveys. The basic study has been applied to (16) wrestlers divided to two equal groups; one is experimental and the other is control group of eight wrestlers per group. Table (1) shows the homogeneity of the sample in the variables (growth - physical - skill performance). 
Table (1)

The moderation of the sample in (growth - physical - skill level) variables $\quad \mathbf{n = 2 3}$

\begin{tabular}{|c|c|c|c|c|c|c|}
\hline \multicolumn{2}{|r|}{ Variables } & Units & Mean & $\overline{\text { St.Div }}$ & Median & Skewness \\
\hline \multicolumn{2}{|r|}{ 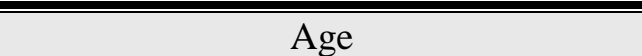 } & year & 21.96 & 1.66 & 22 & -0.18 \\
\hline \multicolumn{2}{|r|}{ Height } & $\mathrm{Cm}$ & 174.74 & 3.81 & 175 & -0.84 \\
\hline \multicolumn{2}{|r|}{ Weight } & $\mathrm{Kg}$ & 79.43 & 7.02 & 79 & 0.58 \\
\hline \multicolumn{2}{|r|}{ Training Age } & Year & 10.22 & 1.65 & 10 & 0.21 \\
\hline \multicolumn{2}{|c|}{ Strength characterized with speed } & $\mathrm{Sec}$ & 5.38 & 0.37 & 5.41 & 0.34 \\
\hline \multirow{4}{*}{ 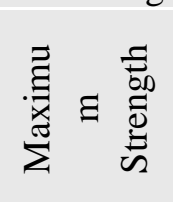 } & Right Fist Strength & Lb. & 110.61 & 3.13 & 110 & 0.37 \\
\hline & Left Fist Strength & Lb. & 111.7 & 3.87 & 111 & 0.17 \\
\hline & Leg Muscles Strength & $\mathrm{Kg}$ & 238.13 & 9.48 & 238 & -0.45 \\
\hline & Back Muscles Strength & $\mathrm{Kg}$ & 140.04 & 7.62 & 140 & -0.37 \\
\hline \multicolumn{2}{|r|}{ Agility } & $\mathrm{Sec}$ & 10.27 & 0.63 & 10.16 & -0.05 \\
\hline \multicolumn{2}{|r|}{ Motor Speed } & $\mathrm{Sec}$ & 1.17 & 0.04 & 1.16 & 0.05 \\
\hline \multirow{2}{*}{ Flexibility } & Horizontal Flexibility & $\mathrm{Cm}$ & 40.04 & 2.68 & 40 & -0.28 \\
\hline & Vertical Flexibility & $\mathrm{Cm}$ & 40.43 & 2.1 & 40 & 0.32 \\
\hline \multicolumn{2}{|r|}{ Skill Level } & Degree & 4.35 & 0.71 & 4 & 1 \\
\hline
\end{tabular}

Table (1) shows that the torsion modulus in physical variables was limited between $(-3,+3)$ which shows the homogeneity of the sample members in these variables.

\section{- Parity of Research Groups}

Table (2)

The arithmetic mean, standard deviation and " $T$ " value and its significance in the variables (growth - physical - skill performance) of two groups (control and experimental)

\begin{tabular}{|c|c|c|c|c|c|c|c|}
\hline \multirow{2}{*}{\multicolumn{2}{|c|}{ Variables }} & \multirow[t]{2}{*}{ Units } & \multicolumn{2}{|c|}{$\begin{array}{c}\text { Experimental } \\
\text { Group } n=8\end{array}$} & \multicolumn{2}{|c|}{$\begin{array}{c}\text { Control Group } \\
n=8\end{array}$} & \multirow[t]{2}{*}{$\mathbf{T}$} \\
\hline & & & Mean & St.Div & Mean & St.Div & \\
\hline & Age & year & 21.25 & 1.48 & 22.12 & 1.55 & 1.15 \\
\hline & Height & $\mathrm{Cm}$ & 176.12 & 3.44 & 176.62 & 1.68 & 0.36 \\
\hline & Weight & $\mathrm{Kg}$ & 80.12 & 4.39 & 81.12 & 9.79 & 0.26 \\
\hline & Training Age & Year & 10.12 & 1.95 & 9,25 & 1.03 & 1.11 \\
\hline \multicolumn{2}{|c|}{ Strength characterized with speed } & $\mathrm{Sec}$ & 5.42 & 0.4 & 5.3 & 0.29 & 0.7 \\
\hline \multirow{4}{*}{ 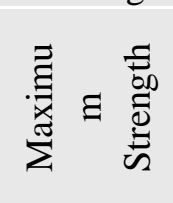 } & Right Fist Strength & Lb. & 110.38 & 2.44 & 111.75 & 3.49 & 0.91 \\
\hline & Left Fist Strength & Lb. & 112.75 & 3.73 & 111.62 & 3.81 & 0.59 \\
\hline & Leg Muscles Strength & $\mathrm{Kg}$ & 236.12 & 11.3 & 238.12 & 10.3 & 0.37 \\
\hline & Back Muscles Strength & $\mathrm{Kg}$ & 138.12 & 9,46 & 140.25 & 7.94 & 0.48 \\
\hline & Agility & $\mathrm{Sec}$ & 10.09 & 0.51 & 10.39 & 0,71 & 0.96 \\
\hline \multirow{3}{*}{ Flexibility } & Motor Speed & $\mathrm{Sec}$ & 1.2 & 0.05 & 1.16 & 0,04 & 1.36 \\
\hline & Horizontal Flexibility & $\mathrm{Cm}$ & 40.12 & 2.47 & 39.75 & 2.71 & 0.28 \\
\hline & Vertical Flexibility & $\mathrm{Cm}$ & 41.62 & 2.5 & 39.62 & 1.84 & 1.81 \\
\hline & Skill Level & Degree & 4.5 & 0.75 & 4 & 0.53 & 1.52 \\
\hline
\end{tabular}

"T" value from the table at $(0.05)=2.145$

Shown from the table (2) that there are insignificant statistical differences between the two groups (control and experimental) in the variable under discussion as the values of "T" calculated is greater than the value of $(\mathrm{T})$ tabulated, which refers to the parity between groups in these variables.

\section{Tools and equipment used in data collection:}

\section{1- Reference Survey:}

The researcher conducted a survey of studies and scientific references that discussed the skill under discussion within the limits available to researcher for the purpose of identification the involved muscles as well as the motor path of the skill. He found the study 
of (Ahmed Amara and Mohammed Al Ashram) (2006)(4) which discussed the motor analysis of the skill and the study of (Mohammed Ismail Al-Jamal) (2007)(23) which discussed the electrolysis of the involved muscles for the same skill. Moreover, identification the different training methods and ways of skill under discussion, getting benefit from them in how to develop the program and the formation of loads and from the results in discussing the results of the current study, as well as determination of the tests to be used in the measurement.

\section{2- Questionnaire (attachment 2)}

The researcher has designed a questionnaire (attachment 1) to solicit the views of experts in the field of study variables through contact and personal interviews to give their opinion about the exercises, determine the most influential fitness elements in skill and to determine the appropriate tests for measurement and program variables, in the period from 01/03/2010 to 31/03/2010 where additions and deletions have been taken into account to suit with the experts opinion.

\section{3- Tests used in research (attachment 4)}

Strength characterized with speed - Maximum Strength (Right and Left Fists Strength Leg and Back Muscles Strength) - Agility - Flexibility - Motor Speed - Level of Skill Performance.

\section{4- Equipment used in research}

Electronic scales to measure weight to the nearest $\mathrm{kg}$ - Restmeter to measure lengths to the nearest $\mathrm{cm}$ - Measuring bar to measure distances - Stopwatchto measure the time per second and to the nearest 0.01 of second - Polar watches- Wrestling Mat - multi weights Wrestling Bodies - Device to measure motor speed (Video Camera, Computer and Time analysis program (Animation Shop 3) - Manometer to measure fist strength - Dynamometer to measure Leg and Back Muscles Strength - GYM contains (Training devices with weights - weights bars of multiple lengths, shapes and weights - Weights pulleys of multiple weights - dumbbell of multiple weights).

\section{5- Data registration form (attachment 3)}

\section{Training Program (attachment 5, 6, 7, 8)}

The training program has been prepared by following these steps:

- The researcher conducted a survey of Arabic and Foreign books within the limits available to researcher.

- The researcher conducted a survey of researches and studies related to the research variables in the field of wrestling training and weightlifting exercises.

- Meeting and contacting the experts in wrestling.

- The main objective of the program

The program aims to - Raise the level of physical performance of wrestlers.

- Raise the level of skill performance of the skill of the reverse body lift.

\section{The training program planning:}

The general training program contains two sub-programs overlapping, namely:

- Muscle strength training program "weightlifting exercises" for the involved muscles resulting from the electrolysis of the muscles. (Attachment 6)

- Directed exercises program in the direction of the motor path of the skill under discussion resulting from kinematic analysis. (Attachment 7)

- The basis of programs development

a) Developing programs according to scientific basis.

b) The training program shall suit the established objectives.

c) The training program and its contents shall suit the age range of the chosen sample. 
d) Program flexibility and its ability to be modified.

e) Benefit from the previous studies that developed training programs.

f) The continuity and regularity in the exercise of the training program to get the desired benefit.

g) Taking into account the principles and foundations of training in the development and writing of the training program training units such as (warm-up - the main part closing).

h) Taking into account the individual differences when developing the program.

i) Taking into account the foundations of weightlifting, which are: good warm-up before the start of weightlifting exercises then good exercise for stretching and flexibility after the end of the weightlifting exercises - theuse of the correct way to breathe - determining the weight used depending on the intensity required by testing the maximum weight to be lifted in one time.

The determinants of the training program

- The period of implementation of the program

The training program will be implemented in the preparation period and before the competitions. The application period of the program has been defined to be (12 weeks) at (4 training units) per week; provided that training starts using weightlifting unit in GYM then exercises units on wrestling mat alternately as follows:

- Saturday: weightlifting training in GYM for the upper part of the body

- Monday: Directed exercises training on wrestling mat

- Wednesday: weightlifting training in GYM for the lower part of the body

- Friday: Directed exercises training on wrestling mat

This must continue until the end of the proposed training program.

The program is divided into three stages as follows:

- Founding Stage (4) weeks

- Preparation Stage (4) weeks

- Pre-competition Stage (4) weeks

- The units of the weightlifting training programs are (24 units)

- The units of the directed exercises training programs on mat are (24 units)

- The period of weightlifting training unit is $120 \mathrm{~min}$

- The period of directed exercises training unit on mat is $120 \mathrm{~min}$

The total time of the program was (5760 min) i.e. (96 hours)

- Training methods used

(Low-intensity periodic training - high-intensity periodic training - Recursive training)

- The formation of training load. (attachment 5)

The researcher used ripple method in the formation of load during program as he used:

$\checkmark$ Formation (3-1), (2-1) and (1-1)

- Determination of the intensity of training loads:

The intensity of training loads was determined where the maximum intensity reached (95-100\%), the intensity lower than the maximum (85-94\%), high intensity (75-84\%), medium intensity (65-74\%), and low-intensity 50-64\%.

- Rationing of training loads:

First: Directed exercises training on wrestling mat. (attachment 7)

The training loads in the directed exercises training were rationed using heart rate by applying the following equation: Target Heart Rate: $(3: 235)$

$=$ Resting heart rate $+[$ Training ratio $\times($ Maximum heart rate - Resting heart rate $)] \ldots$ Where: 
- Average age of sample $=21$ years

- Average Resting Heart Rate of sample $=64$ pulse $/ \mathrm{min}$

- Maximum Heart Rate of sample = 220 - Age = 220 - $21=199$ pulse $/ \mathrm{min}$

- Heart Rate Reserve of sample = Maximum Heart Rate - Resting Heart Rate $=199-64$ $=135 \mathrm{pulse} / \mathrm{min}$

Rationing of training loads using Heart Rate

(Maximum load) (Load less than maximum) (High load) (Moderate load) percentage $95: 100 \%$ percentage $85: 94 \%$ percentage $75: 84 \%$ percentage $65: 74 \%$
Heart rate 192:199 pulse/min Heart rate 178:191 pulse/min Heart rate 165:177 pulse/min Heart rate 152:164 pulse/min

Table (3)

Basis of load formation based on performance time according to Energy Production Systems

\begin{tabular}{|c|c|c|c|c|c|c|}
\hline Energy System & $\begin{array}{c}\text { Exercise } \\
\text { period }\end{array}$ & $\begin{array}{l}\text { Exercise } \\
\text { reps }\end{array}$ & No. of Sets & $\begin{array}{c}\text { No. of } \\
\text { exercise reps } \\
\text { in set } \\
\end{array}$ & exercise : rest & Rest type \\
\hline ATP - PC & $\begin{array}{l}10 \mathrm{sec} \\
15 \mathrm{sec} \\
20 \mathrm{sec} \\
25 \mathrm{sec}\end{array}$ & $\begin{array}{l}50 \\
45 \\
40 \\
32\end{array}$ & $\begin{array}{l}5 \\
5 \\
4 \\
4\end{array}$ & $\begin{array}{c}10 \\
9 \\
10 \\
8\end{array}$ & $1: 3$ & $\begin{array}{c}\text { active rest } \\
\text { (walking and } \\
\text { stretches) }\end{array}$ \\
\hline ATP - PC , LA & $\begin{array}{c}30 \mathrm{sec} \\
40-50 \mathrm{sec} \\
60-70 \mathrm{sec} \\
80 \mathrm{sec}\end{array}$ & $\begin{array}{l}25 \\
20 \\
15 \\
10\end{array}$ & $\begin{array}{l}5 \\
4 \\
3 \\
2\end{array}$ & $\begin{array}{l}5 \\
5 \\
5 \\
5\end{array}$ & $1: 3$ & $\begin{array}{c}\text { light to } \\
\text { moderate } \\
\text { exercises and } \\
\text { Jogging }\end{array}$ \\
\hline $\mathrm{LA}, \mathrm{O}_{2}$ & $\begin{array}{c}1.3-2 \mathrm{~min} \\
2.1-2.4 \mathrm{~min} \\
2.5-3 \mathrm{~min}\end{array}$ & $\begin{array}{l}8 \\
6 \\
4\end{array}$ & $\begin{array}{l}2 \\
1 \\
1\end{array}$ & $\begin{array}{l}4 \\
6 \\
4\end{array}$ & $\begin{array}{l}1: 2 \\
1: 1\end{array}$ & $\begin{array}{l}\text { light to } \\
\text { moderate } \\
\text { exercises }\end{array}$ \\
\hline
\end{tabular}

Second: Weightlifting training. (attachment 6)

The training loads in the weightlifting training were rationed using one repetition maximum for every involved muscles according to selected exercise. (1:193)

Table (4)

Determination of repetitions according to one repetition maximum

\begin{tabular}{|c|c|c|c|c|}
\hline Load Degree & Intensity & "Repetition & Sets & Rest between sets \\
\hline \multirow[b]{2}{*}{ Maximum } & $100 \%$ & $\overline{1}$ & $\overline{1}$ & \multirow[b]{2}{*}{$1.5: 3 \mathrm{~min}$} \\
\hline & $95 \%$ & 2 & $1-3$ & \\
\hline \multirow{4}{*}{$\begin{array}{c}\text { Lower than } \\
\text { Maximum }\end{array}$} & $93 \%$ & 3 & $1-3$ & \multirow{4}{*}{$3: 4 \min$} \\
\hline & $90 \%$ & 4 & $1-3$ & \\
\hline & $87 \%$ & 5 & $3-4$ & \\
\hline & $85 \%$ & 6 & $3-4$ & \\
\hline \multirow{4}{*}{ High } & $83 \%$ & 7 & $3-4$ & \multirow{4}{*}{$3: 5 \mathrm{~min}$} \\
\hline & $80 \%$ & 8 & $3-4$ & \\
\hline & $77 \%$ & 9 & $3-5$ & \\
\hline & $75 \%$ & 10 & $3-5$ & \\
\hline \multirow{2}{*}{ Moderate } & $67 \%$ & 12 & $3-5$ & \multirow{2}{*}{$1.5: 3 \mathrm{~min}$} \\
\hline & $65 \%$ & 15 & $3-5$ & \\
\hline
\end{tabular}

$(6: 121)$

Exercise used in the program.(attachment 8)

First: Directed exercises training on wrestling mat

It depended on the study of (Ahmed Amara and Mohammed Al Ashram) (2006)(4) which performed the quantitative and qualitative analysis of biomechanical characteristics of the skill of the reverse body lift for an international player to determine the technical stages of the skill and know the biomechanical characteristics of the skill stages. (Attachment 9) 
Table (5)

The biomechanical characteristics of the stages of the skill of the reverse body lift (Attachment 9)

\begin{tabular}{|c|c|c|c|c|c|c|}
\hline \multicolumn{3}{|c|}{ Technical Stages } & \multirow[b]{2}{*}{$\begin{array}{c}\text { Biomechanical } \\
\text { Characteristics of the } \\
\text { Stage }\end{array}$} & \multirow[b]{2}{*}{$\begin{array}{c}\text { Motor Sequence of Stage - } \\
\text { Separated }\end{array}$} & \multirow[b]{2}{*}{$\begin{array}{c}\text { Motor } \\
\text { Sequence } \\
\text { of Stage - } \\
\text { Combined }\end{array}$} & \multirow[b]{2}{*}{$\begin{array}{l}\text { Position } \\
\text { distingui } \\
\text { shing } \\
\text { the stage }\end{array}$} \\
\hline & 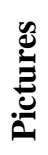 & $\begin{array}{c}\text { Objectiv } \\
\text { e }\end{array}$ & & & & \\
\hline$: \stackrel{\text { : }}{\Xi}$ & $\stackrel{\overparen{f}}{\stackrel{f}{\rightleftarrows}}$ & $\begin{array}{l}\text { Reaching } \\
\text { the initial } \\
\text { position }\end{array}$ & $\begin{array}{l}\text { - Starting the initial position } \\
\text { by increasing pivot area } \\
\text { (one foot backward) } \\
\text { - Increasing balance (bend } \\
\text { knees to half) }\end{array}$ & & & \\
\hline \multirow[b]{2}{*}{$\stackrel{\Xi}{\Sigma}$} & $\begin{array}{l}\widehat{a} \\
\hat{b}\end{array}$ & $\stackrel{\infty}{:}$ & $\begin{array}{l}\text { - Maximum vertical } \\
\text { distance to the center of the } \\
\text { weight of the body } \\
\text { (Stretching knees and torso) } \\
\text { - Having maximum } \\
\text { potential energy (Stretching } \\
\text { knees) }\end{array}$ & & & \\
\hline & $\stackrel{\overbrace{}}{\stackrel{Ð}{\varrho}}$ & $\begin{array}{l}\text { Drag } \\
\text { back and } \\
\text { pushing } \\
\text { by pelvis }\end{array}$ & $\begin{array}{l}\text {-Increase Vertical Speed } \\
\text { (push pelvis up) } \\
\text { - Increase the } \\
\text { resultantacceleration (the } \\
\text { fall of the head and torso } \\
\text { back and down in the } \\
\text { direction of gravity) } \\
\text { - A great deal of force } \\
\text { exerted (tensile by arms in } \\
\text { the direction of the torso + } \\
\text { lifting body on the insteps) } \\
\text { - Total energy (all of the } \\
\text { above within the stage) }\end{array}$ & & & \\
\hline 茎 & $\frac{6}{\mathfrak{n}}$ & $\begin{array}{l}\text { Turnover } \\
\text { and } \\
\text { balance } \\
\text { to } \\
\text { dominate }\end{array}$ & $\begin{array}{l}\text { - Raising one shoulder and } \\
\text { lowering the other (rotation } \\
\text { around the longitudinal axis } \\
\text { of the body) }\end{array}$ & & & \\
\hline
\end{tabular}

\section{Second: Weightlifting training}

It depended on the study of (Mohammed Ismail Al-Jamal) (2007)(23) which performed the electrolysis of the involved muscles for the skill of the reverse body lift for an international player to determine the percentage of work for the involved muscles, which is as follows:

\section{The percentages of participation of the muscular work of the involved muscles of the upper part of body}

1-Brachioradialis muscle

$18 \%$

2-Deltoid muscle

$16 \%$

3-Pectoralis major muscle

$14 \%$

4-Trapezius muscle

$14 \%$

5-Latissimusdorsi muscle

6-Biceps brachii muscle

7-Triceps brachii muscle

8-Rectus abdominis muscle
The percentages of participation of the muscular work of the involved muscles of the lower part of body

1-Vastusmedialis muscle $\quad 21 \%$

2-Rectus femoris muscle $\quad 20 \%$

3 -Semitendinosus muscle $\quad 20 \%$

4-Vastuslateralis muscle $\quad 16 \%$

5-Gastrocnemius muscle $\quad 13 \%$

6-Gluteus maximus muscle $\quad 10 \%$ 


\section{- Surveys}

The researcher selected a random sample of the research community of (7) players outside the basic sample, and he conducted tests on them with the help of assistants, on 08/04/2010 to 20/04/2010.

\section{Study Objective}

-Ensure the safety of the implementation and application of measurements and tests, validity of equipment and tools and related procedures in accordance with the conditions set for them and the suitability of the place.

- Determine the time required for measurement and the time each player takes at each test for measurement.

- Identify the mistakes that we could make during the implementation of tests and measurements and arrange its conduct and their suitability for the age range.

We ensure the appropriate tests to sample as well as the tools and the place of the measurements, as well as to ensure familiarity of assistants on how to conduct the tests in order to avoid measurement errors.

\section{- Scientific coefficients for tests used}

\section{1- Test sincerity}

The researcher calculated sincerity of distinction between two groups; one is not distinguished and it is outside the basic sample while the other is distinguished (surveyed) from 8:11/2010 and each of them consisted of (7) wrestlers.

Table (6)

Indication of the differences between the two groups (distinguished and nondistinguished) in the tests of the research

\begin{tabular}{|c|c|c|c|c|c|c|c|}
\hline \multirow{2}{*}{\multicolumn{2}{|c|}{ Variables }} & \multirow[t]{2}{*}{ Units } & \multicolumn{2}{|c|}{$\begin{array}{l}\text { Distinguished } \\
\text { Group }\end{array}$} & \multicolumn{2}{|c|}{$\begin{array}{c}\text { Non- } \\
\text { distinguished } \\
\text { Group }\end{array}$} & \multirow[t]{2}{*}{$\mathbf{T}$} \\
\hline & & & Mean & St.Div & Mean & St.Div & \\
\hline \multicolumn{2}{|c|}{ "Strength characterized with speed } & $\overline{\mathrm{Sec}}$ & $\overline{5.4}$ & 0.46 & 7.58 & 0.43 & $8.99 *$ \\
\hline \multirow{4}{*}{ 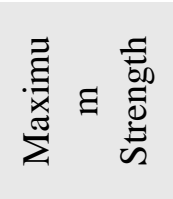 } & Right Fist Strength & Lb. & 109.57 & 3.4 & 92.14 & 4.91 & $7.71 *$ \\
\hline & Left Fist Strength & Lb. & 110.57 & 4.35 & 94.86 & 5.69 & $5.79 *$ \\
\hline & Leg Muscles Strength & $\mathrm{Kg}$ & 240.43 & 6.72 & 207 & 8.42 & $8.2 *$ \\
\hline & Back Muscles Strength & $\mathrm{Kg}$ & 142 & 5.06 & 112.71 & 2.36 & $9.12 *$ \\
\hline \multicolumn{2}{|r|}{ Agility } & $\mathrm{Sec}$ & 10.32 & 0.72 & 13.31 & 0.28 & $10.18 *$ \\
\hline \multicolumn{2}{|r|}{ Motor Speed } & $\mathrm{Sec}$ & 1.17 & 0.04 & 1.58 & 0.07 & $12.58 *$ \\
\hline \multirow{2}{*}{ Flexibility } & Horizontal & $\mathrm{Cm}$ & 40.29 & 3.25 & 31.57 & 1.39 & $6.51^{*}$ \\
\hline & Vertical & $\mathrm{Cm}$ & 40 & 1.41 & 45.29 & 0.75 & $8.72 *$ \\
\hline \multicolumn{2}{|c|}{ Level of Skill Performance } & Degree & 4.57 & 0.78 & 2.43 & 0.53 & $5.96 *$ \\
\hline
\end{tabular}

"T" value from the table at $(0.05)=2.179$

Shown in Table (6) the presence of statistically significant differences in favor of distinguished group, which refers to the sincerity of the tests.

\section{Tests stability}

The researcher calculated tests stability using re-testing on the surveyed sample of (7) wrestlers during 19 and20/04/2010, after a week as interval between the two applications. 
Table (7)

The arithmetic mean, standard deviation and correlation coefficient between the first application and the second application of physical tests under discussion for the surveyed sample

\begin{tabular}{|c|c|c|c|c|c|c|c|}
\hline \multicolumn{7}{|c|}{ surveyed sample } & \multirow{3}{*}{$\frac{\mathbf{n}=(7}{\mathbf{R}}$} \\
\hline \multirow{2}{*}{\multicolumn{2}{|c|}{ Variables }} & \multirow{2}{*}{ Unit } & \multicolumn{2}{|c|}{ First application } & \multicolumn{2}{|c|}{ Second application } & \\
\hline & & & Mean & St.Div & Mean & St.Div & \\
\hline \multicolumn{2}{|c|}{ Strength characterized with speed } & Sec & 5.4 & 0.46 & 5.26 & 0.43 & $0.972^{*}$ \\
\hline \multirow{4}{*}{ 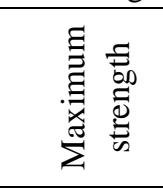 } & Right Fist Strength & Lb. & 109.57 & 3.4 & 110.71 & 2.43 & $0.788^{*}$ \\
\hline & Left Fist Strength & Lb. & 110.57 & 4.35 & 112 & 3.31 & $0.923^{*}$ \\
\hline & Leg Muscles Strength & $\mathrm{Kg}$ & 240.43 & 6.72 & 241.86 & 6.86 & $0.968^{*}$ \\
\hline & Back Muscles Strength & $\mathrm{Kg}$ & 142 & 5.06 & 145 & 6.9 & $0.977^{*}$ \\
\hline \multicolumn{2}{|r|}{ Agility } & $\mathrm{Sec}$ & 10.32 & 0.72 & 10.14 & 0.72 & $0.989 *$ \\
\hline \multicolumn{2}{|r|}{ Motor Speed } & Sec & 1.17 & 0.04 & 1.14 & 0.05 & $0.925^{*}$ \\
\hline \multirow{2}{*}{ Flexibility } & Horizontal & $\mathrm{Cm}$ & 40.29 & 3.25 & 40.71 & 3.14 & $0.905^{*}$ \\
\hline & Vertical & $\mathrm{Cm}$ & 40 & 1.41 & 39.14 & 1.06 & $0.882^{*}$ \\
\hline \multicolumn{2}{|c|}{ Level of skill performance } & Degree & 4.57 & 0.78 & 4.71 & 0.75 & $0.881^{*}$ \\
\hline
\end{tabular}

The tabulated value of " $\mathrm{R}$ " is $(0.754)$ at significance level $(0.05)$

As reflected in the table (7), the value of calculated " $R$ " is greater than the tabulated " $R$ " which indicates the stability of tests under discussion.

- Pre measurements: pre measurements were conducted for members of the research sample from 27 to $30 / 4 / 2010$.

- Setting the maximum weight: 3 days, 4/5/2010.

- Program implementation: the proposed program has been implemented in the period from $8 / 5 / 2010$ to $30 / 7 / 2010$.

- Post measurements: pre measurements were conducted from 31/7 to 3/8/2010 under the same conditions and specifications of the pre measurements and the same place.

- Statistical processing : The researcher has used the following statistical operations in the processing of this study:

- Skewness

-The percentage of improvement
-Median -The standard deviation

-T test -ETA ${ }^{2}$ coefficient
-Arithmetic mean

-Correlation coefficient

\section{Presentation and discussion of the results: First: Presentation of the results:}

Table (8)

Indication of the differences between the two measurements (Pre and Post) of the experimental group for Physical variables and the level of skill performance. $N=(8)$

\begin{tabular}{|c|c|c|c|c|c|c|}
\hline \multirow{2}{*}{\multicolumn{2}{|c|}{ Variables }} & \multicolumn{2}{|c|}{ Pre Measurements } & \multicolumn{2}{|c|}{ Post Measurements } & \multirow{2}{*}{$\mathrm{T}$} \\
\hline & & Mean & St.Div & Mean & St.Div & \\
\hline \multicolumn{2}{|c|}{ Strength characterized with speed } & 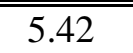 & 0.4 & 3.47 & 0.13 & $15.52 *$ \\
\hline \multirow{4}{*}{ 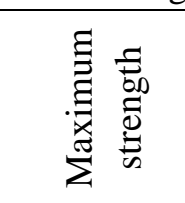 } & Right Fist Strength & 110.38 & 2.44 & 125.12 & 2.47 & $19.07 *$ \\
\hline & Left Fist Strength & 112.75 & 3.73 & 130 & 4.34 & $24.61 *$ \\
\hline & Leg Muscles Strength & 236.12 & 11.3 & 266.75 & 11.24 & $27.81 *$ \\
\hline & Back Muscles Strength & 138.12 & 9.46 & 157.38 & 8.83 & $42.47 *$ \\
\hline \multicolumn{2}{|r|}{ Agility } & 10.09 & 0.51 & 7.14 & 0.47 & $27.22 *$ \\
\hline \multicolumn{2}{|r|}{ Motor Speed } & 1.2 & 0.05 & 0.73 & 0.02 & $23.93 *$ \\
\hline \multirow{2}{*}{ Flexibility } & Horizontal & 40.12 & 2.47 & 34.25 & 2.18 & $19.91 *$ \\
\hline & Vertical & 41.62 & 2.5 & 45.88 & 1.35 & $7.22 *$ \\
\hline \multicolumn{2}{|c|}{ Level of skill performance } & 4.5 & 0.75 & 9.75 & 0.46 & $12.74 *$ \\
\hline
\end{tabular}

The tabulated value of " $\mathrm{T}$ " (1.895) at significance level (0.05) 
Shown in Table (8) the presence of statistically significant differences between pre and post measurements for the experimental group in favor of post measurements in Physical variables and the level of skill performance, where the calculated " $T$ " value is higher than the tabulated value of " $\mathrm{T}$ " for all variables.

Table (9)

Indication of the differences between the two measurements (Pre and Post) of the control group for Physical variables and the level of skill performance.

\begin{tabular}{|c|c|c|c|c|c|c|}
\hline \multirow{2}{*}{\multicolumn{2}{|c|}{ Variables }} & \multicolumn{2}{|c|}{ Pre Measurements } & \multicolumn{2}{|c|}{ Post Measurements } & \multirow{2}{*}{$\mathrm{T}$} \\
\hline & & Mean & St.Div & Mean & St.Div & \\
\hline \multicolumn{2}{|c|}{ 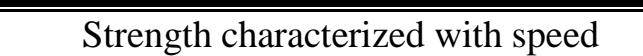 } & 5.3 & 0.29 & 4.27 & 0.45 & *11.18 \\
\hline \multirow{4}{*}{ 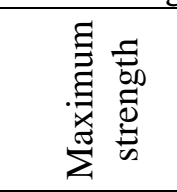 } & Right Fist Strength & 111.75 & 3.49 & 117.5 & 3.16 & $* 15.71$ \\
\hline & Left Fist Strength & 111.62 & 3.81 & 116.62 & 3.62 & $* 13.22$ \\
\hline & Leg Muscles Strength & 238.12 & 10.3 & 252.88 & 11.18 & $* 20.32$ \\
\hline & Back Muscles Strength & 140.25 & 7.94 & 148.88 & 6.03 & $* 9.97$ \\
\hline \multicolumn{2}{|r|}{ Agility } & 10.39 & 0.71 & 8.88 & 0.57 & $* 20.7$ \\
\hline \multicolumn{2}{|r|}{ Motor Speed } & 1.16 & 0.04 & 0.96 & 0.06 & $* 14.62$ \\
\hline \multirow{2}{*}{ Flexibility } & Horizontal & 39.75 & 2.71 & 35.62 & 1.5 & $* 6.75$ \\
\hline & Vertical & 39.62 & 1.84 & 42.62 & 1.3 & $* 6$ \\
\hline \multicolumn{2}{|c|}{ Level of skill performance } & 4 & 0.53 & 5.88 & 0.64 & $* 5.35$ \\
\hline
\end{tabular}

The tabulated value of " $\mathrm{T}$ " (1.895) at significance level (0.05)

Shown in Table (9) the presence of statistically significant differences between pre and post measurements for the experimental group in favor of post measurements in Physical variables and the level of skill performance, where the calculated " $T$ " value is higher than the tabulated value of " $\mathrm{T}$ " for all variables.

Table (10)

Indication of the differences between the two post measurements of the control and experimental group for Physical variables and the level of skill performance. $\mathrm{N} 1=\mathrm{N} 2=(8)$

\begin{tabular}{|c|c|c|c|c|c|c|}
\hline \multirow{2}{*}{\multicolumn{2}{|c|}{ Variables }} & \multicolumn{2}{|c|}{ Experimental } & \multicolumn{2}{|c|}{ Control } & \multirow{2}{*}{$\mathrm{T}$} \\
\hline & & Mean & St.Div & Mean & St.Div & \\
\hline \multicolumn{2}{|c|}{ "Strength characterized with speed } & 3.47 & 0.13 & 4.27 & 0.45 & $* 4.65$ \\
\hline \multirow{4}{*}{ 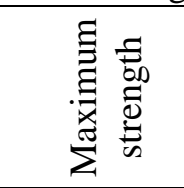 } & Right Fist Strength & 125.12 & 2.47 & 117.5 & 3.16 & $* 5.37$ \\
\hline & Left Fist Strength & 130 & 4.34 & 116.62 & 3.62 & $* 6.68$ \\
\hline & Leg Muscles Strength & 266.75 & 11.24 & 252.88 & 11.18 & $* 2.47$ \\
\hline & Back Muscles Strength & 157.38 & 8.83 & 148.88 & 6.03 & $* 2.24$ \\
\hline \multicolumn{2}{|r|}{ Agility } & 7.14 & 0.47 & 8.88 & 0.57 & $* 6.56$ \\
\hline \multicolumn{2}{|r|}{ Motor Speed } & 0.73 & 0.02 & 0.96 & 0.06 & $* 9.74$ \\
\hline \multirow{2}{*}{ Flexibility } & Horizontal & 34.25 & 2.18 & 35.62 & 1.5 & 1.46 \\
\hline & Vertical & 45.88 & 1.35 & 42.62 & 1.3 & $* 4.88$ \\
\hline \multicolumn{2}{|c|}{ Level of skill performance } & 9.75 & 0.46 & 5.88 & 0.64 & $* 13.86$ \\
\hline
\end{tabular}

The tabulated value of "T" (2.145) at significance level (0.05)

Shown in Table (10) the presence of statistically significant differences between pre and post measurements for the experimental group in favor of post measurements in Physical variables and the level of skill performance, where the calculated " $T$ " value is higher than the tabulated value of " $\mathrm{T}$ " except of the horizontal flexibility test where there is no statistically significant differences. 
Table (11)

Value of the impact of the program "ETA" and the percentage of improvement between (pre / post) measurements for the experimental group in Physical variables and the level of skill performance $\quad n=(8)$

\begin{tabular}{|c|c|c|c|c|c|c|c|c|}
\hline \multirow{2}{*}{\multicolumn{2}{|c|}{ Variables }} & \multicolumn{2}{|c|}{$\begin{array}{c}\text { Pre } \\
\text { Measurements }\end{array}$} & \multicolumn{2}{|c|}{$\begin{array}{c}\text { Post } \\
\text { Measurements }\end{array}$} & \multirow{2}{*}{$\begin{array}{c}\text { ETA }^{2} \\
\text { coefficient }\end{array}$} & \multirow{2}{*}{$\begin{array}{l}\text { percentage of } \\
\text { improvement }\end{array}$} & \multirow[t]{2}{*}{ the direction } \\
\hline & & Mean & St.Div & Mean & St.Div & & & \\
\hline \multicolumn{2}{|c|}{$\begin{array}{c}\text { Strength characterized } \\
\text { with speed }\end{array}$} & 5.42 & 0.4 & 3.47 & 0.13 & 0.97 & $\% 35.97$ & Post \\
\hline \multirow{4}{*}{ 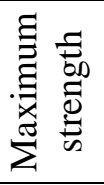 } & Right fist & 110.38 & 2.44 & 125.12 & 2.47 & 0.98 & $\% 13.35$ & Post \\
\hline & Left fist & 112.75 & 3.73 & 130 & 4.34 & 0.98 & $\% 15.29$ & Post \\
\hline & The legs & 236.12 & 11.3 & 266.75 & 11.24 & 0.99 & $\% 12.97$ & Post \\
\hline & The back & 138.12 & 9.46 & 157.38 & 8.83 & 0.99 & $\% 13.94$ & Post \\
\hline \multicolumn{2}{|c|}{ Agility } & 10.09 & 0.51 & 7.14 & 0.47 & 0.99 & $\% 29.23$ & Post \\
\hline \multicolumn{2}{|c|}{ Motor Speed } & 1.2 & 0.05 & 0.73 & 0.02 & 0.98 & $\% 39.16$ & post \\
\hline \multirow{2}{*}{$\frac{\vec{a}}{\bar{a}}: \overrightarrow{\vec{\theta}}$} & Horizontal & 40.12 & 2.47 & 34.25 & 2.18 & 0.98 & $\% 14.63$ & Post \\
\hline & Vertical & 41.62 & 2.5 & 45.88 & 1.35 & 0.88 & $\% 10.23$ & Post \\
\hline \multicolumn{2}{|c|}{$\begin{array}{l}\text { Level of skill } \\
\text { performance }\end{array}$} & 4.5 & 0.75 & 9.75 & 0.46 & 0.95 & $\% 116.66$ & post \\
\hline
\end{tabular}

The results of the table (11) indicate that the value of $\left(\mathrm{ETA}^{2}\right)$ ranged between $(0.88$, 0.99) which shows the strength of the impact of the proposed program to the Physical variables and the level of skill performance of the experimental group and percentage of improvement ranged between $(10.23 \%, 116.66 \%)$ for the (pre / post) measurements for the experimental group in Physical variables and the level of skill performance in the direction of the post measurement.

Table (12)

Value of the impact of the program "ETA" and the percentage of improvement between (pre / post) measurements for the control group in Physical variables and the level of skill performance $\mathbf{n}=(\mathbf{8})$

\begin{tabular}{|c|c|c|c|c|c|c|c|c|}
\hline \multirow{2}{*}{\multicolumn{2}{|c|}{ Variables }} & \multicolumn{2}{|c|}{$\begin{array}{c}\text { Pre } \\
\text { Measurements }\end{array}$} & \multicolumn{2}{|c|}{$\begin{array}{c}\text { Post } \\
\text { Measurements }\end{array}$} & \multirow{2}{*}{$\begin{array}{c}\text { ETA }^{2} \\
\text { coefficient }\end{array}$} & \multirow{2}{*}{$\begin{array}{l}\text { percentage of } \\
\text { improvement }\end{array}$} & \multirow[t]{2}{*}{ the direction } \\
\hline & & Mean & St.Div & Mean & St.Div & & & \\
\hline \multicolumn{2}{|c|}{$\begin{array}{c}\text { Strength characterized } \\
\text { with speed }\end{array}$} & 5.3 & 0.29 & 4.27 & 0.45 & 0.94 & $\% 19.43$ & Post \\
\hline \multirow{4}{*}{ 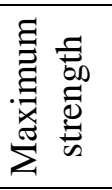 } & Right fist & 111.75 & 3.49 & 117.5 & 3.16 & 0.97 & $\% 5.14$ & Post \\
\hline & Left fist & 111.62 & 3.81 & 116.62 & 3.62 & 0.96 & $\% 4.47$ & Post \\
\hline & The legs & 238.12 & 10.3 & 252.88 & 11.18 & 0.98 & $\% 6.19$ & Post \\
\hline & The back & 140.25 & 7.94 & 148.88 & 6.03 & 0.93 & $\% 6.15$ & Post \\
\hline \multicolumn{2}{|c|}{ Agility } & 10.39 & 0.71 & 8.88 & 0.57 & 0.98 & $\% 14.53$ & Post \\
\hline \multicolumn{2}{|c|}{ Motor Speed } & 1.16 & 0.04 & 0.96 & 0.06 & 0.96 & $\% 17.24$ & post \\
\hline \multirow{2}{*}{ 离: } & Horizontal & 39.75 & 2.71 & 35.62 & 1.5 & 0.86 & $\% 10.38$ & Post \\
\hline & Vertical & 39.62 & 1.84 & 42.62 & 1.3 & 0.83 & $\% 7.57$ & Post \\
\hline \multicolumn{2}{|c|}{$\begin{array}{l}\text { The level of skill } \\
\text { performance }\end{array}$} & 4 & 0.53 & 5.88 & 0.64 & 0.80 & $\% 47$ & post \\
\hline
\end{tabular}

The results of the table (12) indicates that the value of $\left(\mathrm{ETA}^{2}\right)$ ranged between $(0.98,0.80)$ which shows the strength of the impact of the proposed program to the Physical variables and the level of skill performance of the control group and percentage of improvement ranged between $(4.47 \%, 47 \%)$ for the (pre / post) measurements for the control group in Physical variables and the level of skill performance in the direction of the post measurement.

Evaluation of $\mathrm{ETA}^{2}$ coefficient 
(From zero to less than $0.3=$ weak effect), (from 0.3 to less than $0.5=$ Medium effect) $($ From 0.5 to one $=$ strong effect)

\section{Second: Discussion of results}

In light of the previous presentation of the results of the first hypothesis reached by the researcher in the framework of the objectives and research hypotheses and guided by the results of previous studies and what is mentioned in scientific references, the researcher begins to discuss those results as follows:

Shown in Table (8) the presence of statistically significant differences between pre and post measurements for the experimental group in the strength characterized with speed, the strength (the strength of right fist, left fist and the strength of legs muscles and back muscles), agility, motorspeed, (vertical and horizontal) flexibility and the level of skill performance in favor of post measurements where the value of calculated "T" for the experimental group ranged between (15.52), (24.61), (27,61), (42.47), (27.22), (23.93), (19.91), (7.22), (12.74) respectively, which are greater than the tabulated " $T$ " that reached (1.895) at freedom degree of (7) Which indicates that the proposed training program has affected the physical variables under discussion and the level of skill performance.

Shown in table (11) that the value of $\left(\mathrm{ETA}^{2}\right)$ the calculated strength of the impact of the proposed program ranged between $(0.99,0.88)$ and it was greater than $(0.5)$ which shows that the proposed program, directed weights training to the working muscles and directed trainings on the mat in the light of the kinematic analysis, has a great impact and the established exercises were effective in terms of development of anaerobic capacity and physiological variables. This program was on scientific basis and contains individual and couple workouts in which the muscular work is similar to skill performance requirements and at the same kinetic and muscular path which had a great impact on these variables.

These results are supported by the improvement percentage where the results of table (11) indicate the percentage of improvement between the (Pre / post) measurements for the experimental group in the physical fitness variables under discussion in favor of post measurements where the percentage of improvement in the strength characterized with speed reached $(35.97 \%)$, the strength of the right fist $(13.35 \%)$, the strength of the left fist $(15.29 \%)$, leg muscles strength $(12.97 \%)$, the strength of the back muscles $(13.94 \%)$, agility (29.23\%), motor Speed (39.16\%), horizontal flexibility (14.63\%), vertical flexibility $(10.23 \%)$ and the level of skill performance $(116.66 \%)$.This indicates that the proposed training program has led to the development of physical variables under discussion and the level of skill performance, it shows that the physical variables under discussion, which was development through the proposed training program, is the most effective in the level of performance skills of the reverse grab of waist. These results comply with the study of Hamdi Abdel-Rahman (1999)(14), Mohammed Ismail Al Jammal (2007)(23), Ihab El brarie, Mus'ad Hassan (2008)(11), Nabil El Shourbagy (2008)(25), Belal Morsy Witwit (2009)(10).

Shown in Table (9) the presence of statistically significant differences between pre and post measurements for the control group in the strength characterized with speed, the strength (the strength of right fist, left fist and the strength of legs muscles and back muscles), agility, motorspeed, (vertical and horizontal) flexibility and the level of skill performance in favor of post measurements where the value of calculated " $T$ " for the experimental group ranged between (11.8), (15.71), (13.22), (20.32), (9.97), (20.7), (14.62), (6.75), (6), (5.35) respectively, which are greater than the tabulated " $\mathrm{T}$ " that reached (1.895) at freedom degree of (7) Which indicates that the proposed training program has affected the physical variables under discussion and the level of skill performance. 
Shown in table (11) that the value of $\left(\mathrm{ETA}^{2}\right)$ the calculated strength of the impact of the traditional program ranged between $(0.98,0.80)$ and it was greater than $(0.5)$ which indicates that the traditional training program has impact strength.

These results are supported by the improvement percentage where the results of table (12) indicate the percentage of improvement between the (Pre / post) measurements for the experimental group in the physical fitness variables under discussion in favor of post measurements where the percentage of improvement in the strength characterized with speed reached $(19.43 \%)$, the strength of the right fist $(5.14 \%)$, the strength of the left fist $(4.47 \%)$, leg muscles strength $(6.19 \%)$, the strength of the back muscles $(6.15 \%)$, agility (14.53\%), motorspeed (17.24\%), horizontal flexibility (10.38\%), vertical flexibility (7.57\%) and the level of skill performance (47\%). This indicates that the proposed training program has led to the development of physical variables under discussion and the level of skill performance.

The researcher refers these differences and progress to this that traditional training program has led to improvements in the variables under discussion for the control of the group due to the players regularity, their commitment in training and repeating of skill performance, which in turn led to improving the variables under discussion.

It is seen from the table (10) the presence of statistically significant differences between the two groups (experimental / control) in the post measurement of physical fitness elements for the strength characterized with speed, the strength (the strength of right fist, left fist and the strength of legs muscles and back muscles), agility, motorspeed, (vertical and horizontal) flexibility and the level of skill performance in favor of experimental group where the value of calculated " $T$ " was greater than " $T$ " tabulated at significance level of (0.05).Also the value of the calculated " $T$ " ranged (4.65), (5.37), (6.68), (2.47), (2.24), (6.56), (9.74), (4.88), (13.86) respectively, which are greater than the tabulated "T" that reached (2.145) at freedom degree of (14). There is non-statistically significant differences in test of horizontal flexibility found where the value of $(\mathrm{T})$ calculated (1.46), which is smaller than the value (T) tabulated due to the fact of element of flexibility development rate in this advanced age is slightly. There are significant differences in test of vertical flexibility as a result of repeated arcuation during training on reverse grab of waist skill as it shows the importance of vertical flexibility in the main stage where to extend knees joint and raise pelvic during the waist strike, but the arcuation of the back during the final stage on a wide range which does not need to bring the head of the foot during the arcuation, the differences in the rest of the tests indicates that the proposed Training Program has affected the physical variables under consideration and the level of performance skills.

These results are supported by the improvement percentage where the results of table (11), (12) indicate the difference between the percentage of improvement that occurred in level between the proposed program and traditional program.

The researcher believes that these differences are attributed to the improvement of the experimental group due to the proposed training program, which consists of two subprograms (by weights - on the mat) which was applied to the experimental group in physical variables under discussion. Which contains a private individual- even training for the development of these elements, which are similar in muscular work with working muscle and skill performance requirements and the same movement path, indicated by previous studies in terms of importance of electrical analysis of the muscles and kinematic analysis. These results are consistent with Ibrahim Ahmed Gazar (1998)(18), Ibrahim Fawzi Mustafa (1999)(19), Ibrahim Ahmed Gazar (2001)(17), Ihab Mohamed Fawzy Al Badawi (2004)(12), Nabil Hosni Al Shourbagy (2004)(26) this is consistent with the 
privacy principle of the training as well as taking into account individual differences for each player where it is stated by Abdul Aziz Al Nimr and Nariman Al-Khatib (2005)(1), that the performance is improving better if the training is a special type of practiced activity and includes the most important muscles working in this activity and be used in the same way in the competition.

\section{*The conclusions}

In light of the objectives and the nature of this study, within the limits the research sample and the approach used, and the data accumulated by the researcher and the results of the statistical analysis, the researcher reached the following conclusions.

1- The proposed training Program (directed training with weights, directed training with on mat) has positive impact on the development of physical variables affecting skill in reverse grab of waist of the experimental group.

2- The proposed training Program (directed training with weights, directed training with on mat) has positive impact on the development of skill performance level for the experimental group.

\section{*Recommendations}

To the extent that contained in this study of procedures, and the resulting results, the researcher recommends the following:

1- Caring about training with weights during the preparation of wrestlers programs, to raise the levels of strength according to scientific principles and to increase the ability to efficiently wrestle during the games.

2- Caring about directed trainings in the direction of the movement paths of the skill under discussion and various wrestling skills.

3- Caring about refine coaches by holding training courses for them and teach the coaches all modern training methods.

4- The need to design similar programs for various ages.

5- Caring about electrical analysis of muscles working in performance skills to determine the working muscles, which saves time and effort in the training process.

6- Caring about kinematic analysis for skills to determine its movement paths, making it easier and directs the training process.

\section{*References}

1 Abdul Aziz Al nimr, Nariman alKhatib

2

3 Abu El Ela Ahmed AbdelFattah, Ahmed Nasreddin

4 Ahmed Abdul Hamid Ali

Amara, Mohammed Nabawy Al Ashram
(2005) muscle strength and the design of strength programs and planning training season, Alsatzh Sports Book, Giza.

(1996) weights training, The design of strength programs and planning training season, the book publishing center, the first edition, Cairo.

(2003) Fitness Physiology, Dar of the Arab Thought, Cairo.

(2006) quantitative and qualitative analysis of the bio mechanic characteristics of waist reverse grab skill in the Roman wrestling, theories and applications - specialized scientific journal in Physical Education and Sports Science - Faculty of Physical Education for Boys - Alexandria University. 
5 Ahmed Abdul Hamid Ali Amara,

6 Ali Fahmy Beik and others.

7 Mohammed Ali Abdul Rahman

8 Aweys Ali Jabali

9 Badawy Abdel Aal

10 Belal Morsy Witwit

11 Ehab Hamid Alprairie, Massad Hassan Mohamed

12 Ehab Mohamed Fawzy Al Badawi

13 Essam El-Din Abdul Khaliq

14 Hamdi AbdelRahman Al Baghdadi

15 Hisham Subhi Hassan

16 Hosni Sayed Ahmed Hussein

\section{Ibrahim Ahmed Gazar}

(2000) analytical study of the Open Championship of Republic, Roman wrestling in the light of the latest amendments to the Act, published research, Journal of Physical and Sports Sciences, Faculty of Physical Education, University of Menoufia.

(2009) Recent trends in sports training "theories and applications," Part III, version 1, Knowledge facility, Alexandria.

Sports Kinciology, and the fundamentals of kinetic analysis, Dar of the Arab Thought, Cairo,

(2000) sports training between theory and training, Dar MGS

(1987) analysis of the electrical activity in the muscle In aiming with shooting the top through the learning process, unpublished $\mathrm{PhD}$ thesis, Faculty of Physical Education for Girls, Helwan University.

(2009) harmonic capacity and its impact on the kinetic response for skill of waist reverse grab for wrestlers, Ph.D. thesis, Faculty of Physical Education, University of Menoufia.

(2008) The impact of the use of composite training on the development of muscle power and effectiveness of the performance of the skill of reverse waist grab for wrestlers, Tenth International Scientific Conference Sciences Physical Education and Sports, Faculty of Physical Education for Boys, Alexandria University.

(2004), the strategy for training of back throw with the back facing (the back center) through kinematic analysis, published research, theories and applications magazine, No. 53, Faculty of Physical Education for Boys, Alexandria University.

(2003) sports training theories and applications, ed. 13, Knowledge House, Cairo.

(1999) the impact of a Program for the development of muscle ability to perform skills of Twine and waist reverse grab for junior wrestlers, unpublished Master Thesis, Faculty of Physical Education for Boys, Helwan University.

(1993) The impact of a proposed program using some of the assistive devices to improve some of the physical attributes and special level of scorches performance on the pommel horse for junior, unpublished Ph.D. thesis, Faculty of Physical Education for Boys, Alexandria University.

(1992) the impact of the development of the Motor Sensory Perception on some kinematic variables for the front aerobic session, unpublished Ph.D. thesis, Faculty of Physical Education for Boys, Alexandria University.

(2001) biomechanical analysis of the performance of skill back Throw (front center), the scientific journal of the Research and Studies volume II, Faculty of Physical Education in Port Said, Suez Canal University. 
18 Ibrahim Ahmed Gazar

19 Ibrahim Fawzi Mustafa

20 Karbovich,P.V. Sining

21 Layne, Cand Abraham LD

22 Mohammed Ibrahim Shehata

23 Mohammed Ismail Al Gammal

24 Mohamed Reda El Rouby

25 Nabil Hosni El Shourbagy

27 Paul.J.\&Duane, K

28 Reem

Mohammed El Dessouky

29 Talha Hossam El-Din

30

31
(1998) kinematic analysis of the performance of bridge skill in wrestling, the first volume of the Scientific Research Conference on Sport and the development of the Arab community and the requirements of the twenty-first century, the Faculty of Physical Education for Girls in Al jazeera, Helwan University.

(1999) contribution some kinematic characteristics and special physical attributes on performance skills of back throw in wrestling, unpublished Master Thesis, Faculty of Physical Education in Port Said, Suez Canal University.

(1971)Physiology of muscular activity sauder company, philadelphia,.

(1987) Patterns of lower limb muscle activity in young boys during a one foot static balance task R.Q.VOL.58 NO 1.

(2003) Modern Gymnastics training, of the Arab Thought Dar, the first edition, Alexandria University.

(2007) The impact of force proposed training program to improve the degree of waist reverse grab skill in Roman wrestling, unpublished Master Thesis, Faculty of Physical Education for Boys, Helwan University.

(2005) principles of training in the sport of wrestling, Mahi printings, Alexandria, version 1.

(2008) the impact of the use of certain muscle power development methods on the effectiveness of the performance of the waist reverse grab skill for wrestlers, tenth International Scientific Conference of Sciences physical education and sport, Faculty of Physical Education for Boys, Alexandria University.

(2004) strategy for the training of leg screw skill Grill) through kinematic analysis, published research, theories and applications magazine, No. 53, Faculty of Physical Education for Boys, Alexandria University.

(1999)Biomechanics

in

http://www.Explorespacenotdrugs.com/Biomechanic. Html, (2002) The impact of the use of quality training program to raise the performance level of skill of front somersault on the hands for junior on jump horse, Master Thesis, University of Alexandria.

(1998) Applied Movement Science, Part I, version 1,book publishing center.

(1995) The kinetic and functional basis for athletic training, Dar of the Arab Thought, Cairo.

(1994) The kinetic and functional basis for athletic training, Dar of the Arab Thought, Cairo. 